\title{
Serum insulin-like growth factor 1 in congenital heart disease
}

\author{
J S Barton, P C Hindmarsh, M A Preece
}

\begin{abstract}
Serum insulin-like growth factor 1 (IGF1), insulin-like growth factor binding protein-3 (IGFBP-3), and a range of growth and nutritional variables were investigated in 62 infants with congenital heart disease and healthy controls. Infants with congenital heart disease were small, underweight, and had a reduced energy intake. Serum IGF-1 and IGFBP-3 concentrations were significantly reduced. Decreased IGF-1 and IGFBP-3 levels are observed in nutritional deficiency; similar findings in congenital heart disease suggest that undernutrition contributes to the poor growth of these infants. Serial measurements of serum IGF-1 and IGFBP-3 may be helpful in monitoring the effect of nutritional treatment in congenital heart disease.

(Arch Dis Child 1996;75:162-163)
\end{abstract}

Keywords: congenital heart disease, insulin-like growth factor I, insulin-like growth factor binding protein-3.

Poor growth is a well recognised complication of severe congenital heart disease, ${ }^{1}$ and may result from both a reduction in energy intake and increased energy expenditure. ${ }^{2}$

Insulin-like growth factor $1(\mathrm{IGF}-1)$ is a growth hormone dependent peptide which is associated in the circulation with specific binding proteins and plays an important role in tissue growth and differentiation. ${ }^{3}$ Insulin-like growth factor binding protein 3 (IGFBP-3) represents the major IGF-1 binding protein in serum and acts to maintain a circulating store of IGF-1 and prevent large fluctuations in IGF-1 activity within tissues. ${ }^{4}$ We have measured serum IGF-1 and IGFBP-3 in children with congenital heart disease and related these findings to their growth and nutritional intake in order to explore further the growth failure observed in these patients.

The Growth Research Centre, The Medical Unit, Institute of Child Health, Guilford Street, London JS Barton

PC Hindmarsh

MA Preece

Correspondence to: Dr JS Barton, Bristol Royal Hospital for Sick Children St Michael's Hill, Bristol BS2 8BJ.

\section{Methods}

Sixty two infants ( 31 boys) were investigated at a mean age of 1.06 (SEM 0.09) years. They had all presented within the first year of life with symptomatic congenital heart disease (table 1) and subsequently required cardiac catheterisation or surgery, allowing blood samples to be drawn. Patients with additional congenital abnormalities or a recognisable dysmorphic syndrome were excluded.

Serum IGF-1 was measured by specific radioimmunoassay and IGFBP- 3 by immunoradiometric assay (DSL-6600 Diagnostic Systems Laboratories; Webster, Texas, USA). The results have been related to growth and to food intake estimated from a three day dietary record and analysed using computerised food composition tables (Diet 2000, B\&W Electronic Systems, Portsmouth, UK). Normal values for serum IGF-1 and IGFBP-3 were obtained from two groups of healthy age matched control infants.

Results are expressed as the mean and standard error or, for log transformed data, as the geometric mean and $95 \%$ confidence interval $(95 \% \mathrm{CI})$. Group differences were investigated by Student's $t$ test. A p value of $<0.05$ was considered significant. Forward stepwise regression analysis was used to explore the variance in serum IGF-1 levels.

The study was approved by the research ethics committee of The Hospital for Sick Children, and parental consent was obtained in all cases.

\section{Results}

The birth weight of the infants with congenital heart disease was slightly reduced (mean birthweight SDS $-0.37,95 \%$ CI -0.63 to -0.11 ), with further postnatal growth retardation apparent by the time of study; those with cyanosis were shorter than acyanotic infants but weight, body mass index (BMI), and head circumference were similar (table 2).
Table 1 Congenital heart disease: diagnoses

\begin{tabular}{lc}
\hline Diagnosis & No of patients \\
\hline Ventricular septal defect ( + / - coarctation) & 16 \\
Tetralogy of Fallot & 11 \\
Complex cyanotic heart disease (double outlet right ventricle, tricuspid atresia, transposition + pulmonary & 11 \\
$\quad$ stenosis) & 9 \\
Pulmonary atresia ( + / - VSD) & 4 \\
Transposition of great arteries & 2 \\
Atrioventricular septal defect & 2 \\
Total anomalous pulmonary venous drainage & 7 \\
Other (common arterial trunk, atrial septal defect, patent arterial duct, coarctation, pulmonary stenosis) & \\
\hline
\end{tabular}


Table 2 Growth and laboratory data on infants with congential heart disease (CHD) and controls; mean (SE)*

\begin{tabular}{|c|c|c|c|c|c|c|c|c|}
\hline Group & No & Age & Length SDS & Weight SDS & $B M I S D S$ & OFC SDS & $I G F-1(n g / m l)$ & $I G F B P-3(n g / m l)$ \\
\hline CHD (acyanotic) & 28 & $0.83(0.09)$ & $-0.48(0.23)$ & $-1.82(0.26)$ & $-2.08(0.23)$ & $-1.94(0.26)$ & $29(21-40)$ & $1.16(0.08)$ \\
\hline CHD (cyanotic) & 34 & $1.26(0.14)$ & $-1.38(0.17)^{\star \star}$ & $-1.63(0.23)$ & $-1.63(0.23)$ & $-1.93(0.22)$ & $32(23-44)$ & $1.29(0.07)$ \\
\hline Controls I & 40 & $1.13(0.14)$ & $0.26(0.26) \dagger$ & $-0.27(0.21) \dagger$ & $-0.27(0.21) \dagger$ & - & $61(55-67) \ddagger$ & - \\
\hline Controls II & 86 & $1.17(0.09)$ & - & - & - & - & - & $1.45(0.06) \Upsilon$ \\
\hline
\end{tabular}

${ }^{\star}$ Except IGF-1 data where the geometric mean and $95 \%$ confidence interval for log transformed data are shown. SDS = standard deviation score; OFC = occipitofrontal head circumference.

Acyanotic $v$ cyanotic CHD: ${ }^{\star}$ length SDS, $\mathrm{p}=0.002$; weight SDS, BMI SDS, and OFC SDS, $\mathrm{p}=\mathrm{NS}$

CHD $v$ controls: + length SDS, $†$ weight SDS, and + BMI SDS all $\mathrm{p}<0.0015$

IGF-1: $\neq p=2.8 \times 10^{-7} v$ CHD infants.

IGFBP-3: $\uparrow \mathrm{p}=0.014 v$ CHD infants.

Energy intake $(n=52)$ was variable. Mean daily energy intake was $3.34 \mathrm{MJ}(776 \mathrm{kcal})$ ( $95 \%$ CI 2.98 to $3.74 \mathrm{MJ}$ ), but was lower than expected for age, with a mean of $93 \%$ (95\% CI $87 \%$ to $100 \%$ ) of estimated average requirements (\%EAR).

Serum IGF-1 concentrations were unrelated to age or sex in congenital heart disease infants or controls and did not differ between infants with and without cyanosis, $t=-0.421, \mathrm{p}=$ 0.7 . Infants with congenital heart disease had lower IGF-1 concentrations than controls, $t=$ $-5.6, p<0.001$. Among those with congenital heart disease, IGF-1 was most closely correlated $(r=0.33)$ with \%EAR, while a BMI SDS of $<-2.0(n=29)$ was associated with lower serum IGF-1 concentrations $(23 \mathrm{ng} / \mathrm{ml})$ than a BMI SDS of $>-2.0(38 \mathrm{ng} / \mathrm{ml})(\mathrm{n}=$ 29); $t=-2.295, \mathrm{p}=0.03$. The regression model which best explained IGF-1 used both \%EAR and BMI, but excluded age, length, weight, arm circumference, and skinfold thickness as covariates:

$$
\begin{aligned}
& \mathrm{IGF}-1=2.7(0.53)+0.01(0.005) \% \mathrm{EAR} \\
& +0.16(0.1) \mathrm{BMI} \\
& \quad\left(\text { residual SD }=0.84 ; \text { adjusted } \mathrm{R}^{2}=14 \%\right) .
\end{aligned}
$$

Mean IGFBP-3 concentrations were also reduced in congenital heart disease compared with controls and were similar in cyanotic and acyanotic congenital heart disease $(p=0.22)$ (table 2).

\section{Discussion}

The small size of the infants with congenital heart disease studied largely reflected postnatal growth failure, with some differences observed between cyanotic and acyanotic infants. Acyanotic infants were markedly underweight with less impairment of linear growth, while cyanotic infants showed equally impaired length and weight gain, although differences in body mass index were not statistically significant. Head growth was equally impaired in both groups.

Energy intake was lower than expected for age in all types of congenital heart disease. Although the reduction in energy intake was small, the estimated intake (\%EAR) was correlated with both weight SDS $(r=0.40)$ and serum IGF-1 $(r=0.33)$.

Little attention has been paid to the endocrine milieu in congenital heart disease.
Raised plasma growth hormone concentrations have been reported in patients with congenital heart disease and growth retardation, ${ }^{5}$ while in an experimental model of cyanotic congenital heart disease, newborn lambs had significantly reduced serum IGF-1 and IGFBP-3 concentrations. ${ }^{6}$ Similar studies have not been performed in human subjects with congenital heart disease. The previously reported increase in plasma growth hormone in congenital heart disease and our findings of a significant reduction in serum IGF-1 and IGFBP-3 concentrations in growth retarded infants with various congenital cardiac defects are consistent with a state of growth hormone insensitivity frequently seen in nutritional deficiency. However, given the poor fit of the regression model derived from our infants with congenital heart disease, factors other than those studied must be important in determining circulating IGF-1 levels.

An energy intake of $0.65 \mathrm{MJ} / \mathrm{kg} / \mathrm{d}(150 \mathrm{kcal} /$ $\mathrm{kg} / \mathrm{d}$ ) may be necessary for normal weight gain in infants with congenital heart disease ${ }^{2}$ and often requires enteral feeding of an enriched infant formula. Serial measurements of serum IGF-1 and IGFBP-3 may be a useful adjunct to anthropometric assessment in monitoring nutritional support in these infants.

We thank the physicians and surgeons of the cardiothoracic unit, Hospital for Sick Children, Great Ormond Street, for permission to study their patients, and Pharmacia, Stockholm, Sweden, for their support of this study. Serum samples on healthy children were kindly provided by the late Professor Mowat, King's College Hospital, London. JSB and PCH Mowat, King's College Hospital, London. JSB and PCH are generously supported by Children Nationwide and Pharmacia. This work was presented in part at the 4th Joint Lawson Wilkins ric Endicrinology meeting, San Francisco, June 3-7, 1993.

1 Mehrizi A, Drash A. Growth disturbance in congenital heart disease. F Pediatr 1962;61:418-29.

2 Barton JS, Hindmarsh PC, Scrimgeour CM, Rennie MJ, Preece MA. Energy expenditure in congenital heart disease. Arch Dis Child 1994;70:5-9.

3 Zapf J, Schmid CH, Froesch ER. Biological and immunological properties of insulin-like growth factors (IGF) I and II. Clin Endocrinol Metab 1984;13:3-30.

4 Baxter RC. Insulin-like growth factor binding proteins in the human circulation: a review. Hormone Res 1994; 42:140-4.

5 Ikkos DD, Thanopoulos V, Ikkos DG. $24 \mathrm{~h}$ plasma levels of growth hormone in growth retardation of children with congenital heart disease. Helv Paediatr Acta 1974; 29:583-8.

6 Bernstein D, Jasper JR, Rosenfeld RG, Hintz RL. Decreased serum insulin-like growth factor I associated with growth failure in newborn lambs with experimental cyanotic heart disease. $\mathcal{F}$ Clin Invest 1992;89:1128-32. 